\title{
LIVE-LANÇAMENTO DE LIVRO DO PROF. DR. ROBERTO SIDNEI MACEDO
}

MACEDO, Roberto Sidnei. A pesquisa como heurística, ato de currículo e formação universitária. Aula inaugural. Live Youtube. POSEDUC UERN, 15 set. 2020. Disponível em: https://www.youtube.com/watch?v=t6a_9qPvjic. Acesso em: 08 fev.2020.

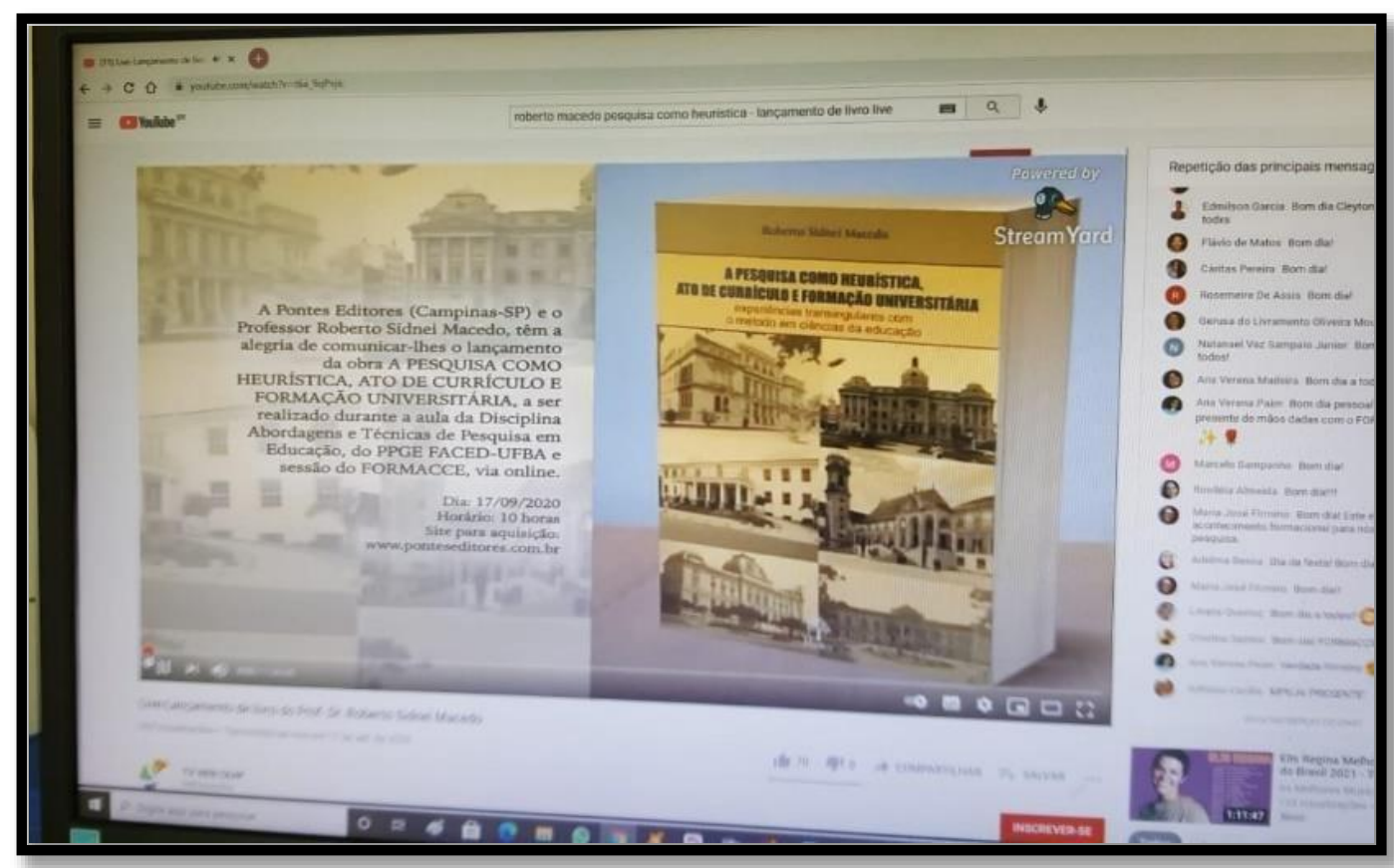

Mirian Maia do Amaral ${ }^{1}$

\section{SOBRE O AUTOR DO LIVRO}

Roberto Sidnei Macedo é psicólogo, educador, Professor Titular e atual Diretor da Universidade Federal da Bahia, e pesquisador em Educação, dos campos do currículo eda formação, há, aproximadamente, 20 anos. Roberto Sidnei Macedo é,

Submetido em: 28/03/2021 - Aceito em: 07/07/2021 - Publicado em: 12/07/2021

${ }^{1}$ Fundação Getulio Vargas 
ainda, coordenador do Grupo de Pesquisa FORMACCE, da UFBa.

\section{SOBRE O CONTEÚDO DA LIVE}

Essa live foi promovida pelo Programa dePós-graduação em Educação da Universidade do Rio Grande do Norte - POSEDU/UERN, sob a coordenação da professora Denise Guerra e do professor Joaquim Barbosa, em 15 set. 2020. Realizada no âmbito da disciplina EDC 557 - Abordagens e técnicas de pesquisa em educação Mestrado e Doutorado, em sessão aberta do Grupo FORMACCE - UFBA. objetivou o lançamento do livro "A pesquisa como heurística, ato de currículo e formação universitária: experiências transingulares com o método em ciências da educação". Campinas, SP: Pontes Editores, 2020, de autoria de Roberto Macedo.

Nela, o autor narra a experiência de escrever essa obra, discutindo a pesquisa universitária, um tema de grande relevância para a Educação e para todos aqueles que queiram vislumbrar, para além dos padrões regulatórios, itinerâncias, errâncias metodológicas da heurística e da formação, tão presentes em nossos cotidianos. A apresentação, apoiada em diferentes telas, é feita por meio de videoconferência, estruturada em três grandes blocos: (a) Problemáticas; (b) Afirmação das especificidades; e (c) Dispositivos de pesquisa e experiência, heurístico-formacional.

Inicialmente, a Tela 1 reproduz a capa do livro, na qual podemos observar algumas imagens de universidades históricas, particularmente da UFBa, lócus de atuação de Macedo, que nos revela, então, a existência de algumas transversalidades em seu processo de escrita do livro, além de uma implicação fundamental: afirmar a universidade como instituição necessária às sociedades humanas, que precisam do saber social e culturalmente referenciado. Numa perspectiva mais ampla, essa construção se sustentou em três movimentos: (a) entender a pesquisa universitária, a partir do olhar do que é a educação universitária; (b) o cotidiano na universidade, como vetor na construção do saber, compromissado com a formação, dado que a experiência é atualizada, mediante atos de currículo; e (c) a aprendizagem universitária, expressa na qualificação da formação universitária, como diferencial no cenário educacional. 
As Telas 2 e 3 apresentam o conjunto de problemáticas; ou seja, as temáticas objeto de sua fala, das quais as três primeiras - a criação da obra e suas implicações universitárias; heurística e atos de currículo; e formação --, foram, anteriormente, mencionadas e, daqui pra frente, serão aprofundadas.

Nesse ponto, Macedo ressalta suas implicações com a obra. Importante pontuar que, para aqueles que conhecem os escritos de Macedo, essas implicações são resultantes de um longo processo por ele vivenciado com e pela pesquisa, no qual a 'scuta sensível', o olhar plural, o pensamento crítico-reflexivo, e suas realizações heurístico-formacionais, junto ao Grupo FORMACCE, credenciaram-no à escrita dessa obra.

Partindo do princípio de que a universidade não deve ser vista apenas como um 'espaçotempo' de construção dos conhecimentos, mas, também de formação, Macedo ressalta o momento atual em que as universidades públicas, especialmente às mais populares, sofrem ataques constantes, cortes orçamentários, precarização do ensino; um verdadeiro retorno à idade média. Durante sua explanação, muito coerente com todo o pensamento desenvolvido ao longo de sua vida e das obras já publicadas, é possível perceber a implicação do autor com o ato de pesquisar, quando afirma que a pesquisa, como heurística, atos de currículo e formação é criação, inventividade, descoberta e identificação de singularidades. Não é algo predefinido. Ela se desenvolve, mediante currículos 'praticadospensados', e vai se atualizando, na universidade, nos diferentes trabalhos, debates, encontros e crítica. Desse modo, o método, como um conjunto de experiências acumuladas, vai se materializando, ao longo da investigação, marcado por nossas itinerâncias e errâncias, e pelos acontecimentos que atravessam nossos cotidianos.

Dado que a formação é irredutível e inexplicável, o currículo se constitui, também, como um 'fazersaber' experencial, ainda que no processo investigativo saberes eleitos como formativos dialoguem com o currículo em fluxo (atos de currículo), nos diferentes 'espaçostempos', com suas políticas de sentido (Macedo 2010). Explicá-la só é possível, se as pessoas nos revelarem, de alguma forma, como 


\section{Revista Docência e Cibercultura}

estão aprendendo e se formando. É fundamental, portanto, que a educação universitária valorize a experiência e o vivido, para trazer a história cultural da educação.

Para o autor, a universidade, principal núcleo de produção de conhecimento e desenvolvimento do pensamento crítico, vem sendo 'calada', nos últimos tempos, perdendo espaço, com o excesso de normatização e redução de sua autonomia. Exemplo disso, é o que se refere à pesquisa etnográfica, que exige um tempo significativo de imersão no campo, haja vista a exigência de uma escrita apoiada em descrição densa, da pertinência dos detalhes e de processos refinados. Desse modo, o período de 2 anos de um curso de Mestrado é insuficiente para sua adoção; o que se faz é tomá-la como inspiração, estudando as teorias que a sustentam, deixando para experenciá-la no Doutorado. Ademais, o neotecnicismo graça, livremente, com seus controles e excessos regulatórios, como, por exemplo, a exigência de publicação em Revistas Qualis A e B; a intervenção dos Conselhos de ética nas opções metodológicas dos estudantes; a não valorização das histórias heurísticas e formacionais dos estudantes; e a cultura dos padrões fixados e corporativos, movida por interesses e poder.

Sob essa ótica, Macedo enfatiza que o o produtivismo, com todos os seus desdobramentos, acaba por destruir o espírito crítico e a liberdade de criação, sendo necessário conquistar os 'elos perdidos', mediante uma pesquisa aprendente, pautada num rigor outro e plural, e transversalizada por compreensões curriculares e inspirações heurísticas e formacionais, com base em nossas experiências.

O autor traz, à cena, a 'Carta, a um jovem investigador em educação' , escrita por Nóvoa (2015), da qual destaca alguns pontos que considera essenciais, como, por exemplo: (a) 'conhecer bem as regras que pautam a ciência, mas não deixar de arriscar e transgredi-las', dado que 'a investigação ou é criação ou não é nada'. O que importa, na ciência, é a capacidade de ver de outro modo, de pensar de outro modo. Se repetirmos o mesmo, encontraremos o mesmo. Sem transgressão não há descoberta, não há criação, não há ciência; (b) 'conhecer para além dos limites da ciência', lendo, lendo muito, lendo devagar coisas diversas, coisas inúteis. É preciso pensar, refletir muito, conquistar o tempo de pensar. As ideias novas estão 
na fronteira, porque esse é o lugar do diálogo e dos encontros; (c) 'conhecer para além das evidências', habituando-se a ultrapassar o já sabido e aprendido, pois essa área está saturada de ideias e de certezas, quase sempre definitivas. O problema não está na diversidade, nem sequer na abundância de opiniões, pois todas são legítimas. O problema está na forma como se misturam e se entrelaçam - como se todas tivessem o mesmo valor, pontua Macedo; e (d) 'conhecer com liberdade e pela liberdade', pois a universidade é, sobretudo, um 'espaçotempo' de liberdade. No princípio, e no fim da investigação, está sempre a liberdade. É para isso, e por isso, é preciso trabalhar, pensar e escrever.

Nas Telas 3 e 4, Macedo afirma que 'sem conhecimento, sem criação, sem cultura, não há futuro para este país, que parece outra vez perdido', trazendo alguns argumentos crítico-explicativos que sustentam suas afirmações, como:

(a) a necessidade de se duvidar sempre das reduções e simplificações presentes nas avaliações oficiais, cujos métodos não levam em conta as condições locais, contextuais, socioculturais, sociotécnicas e existenciais, assumindo padrões homogeneizantes. Na pesquisa universitária não 'usamos ou aplicamos' métodos. O método é para ser compreendido, aprofundado, experimentado, experenciado. Método é itinerância e revela nossa capacidade de interferir na realidade, devendo ser inventado, bricolado, customizado, porque a pesquisa é uma 'aventura pensada' e valorada; uma experiência de autorização curricular-formacional complexa.

Macedo enfatiza que o método vai se materializando, ao longo da pesquisa, mediante um rigor outro (diferente) e plural, alicerçado na capacidade sociotécnica, nas competências científica, política (melhor dispositivo), ética, cultural, estética (sensibilidade) e implicacional (modo de criação de saberes - sem sobreimplicação). Nesse contexto, não lidamos com objetos ou dados e, sim, com compreensões situadas. (construção);

(b) a formação acontece com e pela pesquisa e a inteligibilidade institucional da universidade. É preciso atentar para suas normas, controles, exigências, e para a questão do tempo. Nesse contexto, processos formativos emergem como experiências 
fundamentais na educação universitária, como a autoformação (aprender consigo mesmo), a heteroformação e a ecoformação (aprendercom o outro e com os objetos, a erosformação (desejo de saber - "sem tesão, não há solução; sem desejo, não há criação") e a metaformação (olhar para si; para sua própria formação), na qual o Diário de Campo ganha relevância, pois possibilita avaliar itinerâncias e errâncias, e refletir sobre o próprio processo de aprendizagem.

Nas Telas 5 e 6, Macedo enfatiza que, em relação aos dispositivos de produção de informação e compreensões na pesquisa heurístico-formacional - qualquer pesquisa acadêmica e científica deve levar em conta recomendações epistemológicas e metodológicas, que ofereçam sustentação às ideias e proposta apresentadas. Nessa perspectiva, além da necessidade de clareza, coerência, concisão e consistência (4 Cs), a construção de um projeto de pesquisa deve levar em conta ao fato de a pesquisa lidar com o devir (experimentar a incerteza, a insuficiência e a incompletude, sem perder de vista o compromisso com a pertinência e a relevância de sua problemática e da elaboração de seu constructo).

$\mathrm{Na}$ estruturação do projeto é fundamental evitar digressões teóricas, epistemológicas e metodológicas, observados a estética e o estilo, sem perder a poética. O campo, por sua vez, não está a nossa espera, enfatiza Macedo. Ele tem vida e é estruturante de nossa pesquisa; nele há pessoas, ações e realizações; há também surpresas e acontecimentos fecundos e desafiadores. 'Espaçotempo' de diálogo, o campo nos olha, sente-nos, interpreta-nos, cria pontos de vista sobre nós, vai nos identificando e nos alterando ao interagir conosco. É preciso garantir uma preparação e uma relação criterizada e qualificada com o campo e os participantes da pesquisa, conforme suas especifidades.

Quanto à produção de informações e compreensões, não basta constatar e revelar. É preciso objetivar nossas compreensões. O trabalho e a arte da compreensão, com e para além do constatável, caracteriza um processo de análise, no qual a autoria (ser autor de uma obra complexa, que é a própria pesquisa, porque rigorosa acadêmica, científica e socialmente) e a autorização (ou seja, ser autor de si mesmo devem ser 


\section{Revista Docência e Cibercultura}

exercitadas.

Macedo nos alerta para a responsabilidade com a temporalidade a ser vivida na experiência; não apenas em função do chronos - tempo do relógio, mas também do kairós - tempo da criação. Daí a importância de buscarmos o equilíbrio entre os tempos acadêmicos e científicos vividos e o das instituições a que nos vinculamos. Em relação ao desejo de saber e se formar com e pela pesquisa, o autor ressalta que os desejos que nos movem para a realização de uma pesquisa universitária não devem se alienar no desejo do outro. Renunciar ao gozo, como modo de vida, é experimentar vivo a morte: 'Sem tesão não há criação', enfatiza. A alegria, o prazer e a paixão pelo que fazemos mobilizam forças criativas, a ponto de, muitas vezes, não reconhecermos nossa própria autoria. Desse modo, Macedo enfatiza que a aula, a pesquisa e a escrita nos fazem viver, curando-nos.

Finalmente, na Tela 7, Macedo conclui sua explanação, afirmando que: "não se faz pesquisa, nem se forma com ela, com um cérebro separado da complexa experiência de quem aprende na universidade, e sua biografia heurístico-formacional e formativa (2020). Desse modo, compreende que a pesquisa como criação, itinerância e (trans) formação não pode ser apartada da universidade, de sua história e de sua cultura.

\section{DO DEBATE}

Após seus agradecimentos, e passada a palavra à coodenadora Denise Guerra, deu-se início ao debate, no qual Macedo reafirmou aspectos fundantes de sua fala, como por exemplo: (a) a necessidade do cuidado e atenção à universidade contra os ataques que vêm sendo agutizados; (b) a pesquisa como lugar de aprendizagem e realização 'fazersaberser'; (c) pesquisa é mais que produzir uma dissertação e uma tese': é busca constante pelo saber; (d) pesquisa não pode se reduzir ao viés aplicacionista - há necessidade de autorização e de autoria, sendo possível, nos cursos de mestrado e doutorado profissionais, o desenvolvimento de uma pesquisa heurístico-formacional propositiva, entre outras. 


\section{Revista Docência e Cibercultura}

\section{Crítica da Resenhista}

A live nos brinda com o lançamento do livro de Roberto Macedo, um de nossos principais quadros teórico-metodológicos, e fornece subsídios as nossas pesquisas científicas, deixando claro que, para além dos padrões regulatórios e controles excessivos, tão presentes em nossos cotidianos, a pesquisa se realiza como uma especificidade vinculada à universidade, sua história e cultura acadêmica. E o faz, de forma singular, criativa e autoral, entendendo-a como descoberta/criação; como atos de currículo que se dão a partir de propostas curriculantes de gestores, professores e estudantes, ao produzirem seus saberes, ao longo do processo de investigação, nos seminários, nas aulas, nos grupos, entre outros. Nessa perspectiva, considera não apenas a aquisição dos conhecimentos no âmbito da universidade (instituído), mas, também a sua experiência como autor de diversos estudos, pesquisador implicado e orientador, ao longo de mais de 20 anos.

O livro, ora lançado, consiste numa obra atual, necessária e relevante; um diferencial na literatura da área, que nos ajuda a pensar a prática da pesquisa heurísticoformacional, em tempos críticos, especialmente, para as universidades públicas, que vivem tempo de negacionismo e ataques os mais diversos; o que nos exige resiliência e resistência.

No entanto, a compreensão adequada dessa obra requer conhecimentos anteriores, para que a aprendizagem se faça de modo significativo (ou seja, a estrutura cognitiva seja ampliada, mediante a incorporação de novas ideias, como por exemplo: o que são atos de currículo; como se dá a formação; conceitos referentes a métodos/metodologia de pesquisa, dispositivos, ambiências formacionais, entre outros, o que pressupõe certa familiaridade com leituras de outras obras do autor, em conexão com os interlocutores de seus escritos. Com estilo claro e objetivo, Macedo apresenta sua proposta, impulsionando- nos à reflexão crítica, levando-nos a (re)pensar nosso plano de pesquisa. Desse modo, ajuda-nos a compreender a atividade científica, oportunizando-nos analisar e confrontar vários posicionamentos, a fim de chegarmos as nossas próprias conclusões. 
Por fim, ressalto a relevância da obra, ora lançada, para todos aqueles que atuam na pós-graduação lato e stricto sensu, e que se interessem por pesquisas, sem amarras e para além dos padrões regulatóros, ao tempo em que os convido a conhecer essa obra, que tem como ponto crucial a experiência heurístco-formacional na construção dos saberes na educação universitária.

\section{REFERÊNCIAS}

MACEDO Roberto Sidnei. MACEDO, Roberto Sidnei. Compreender/mediar a formação: o fundante da educação. Brasília: Líber Livros, 2010.

MACEDO Roberto Sidnei. Atos de currículo e formação: o príncipe provocado. Revista Teias. Currículos: problematização em práticas e políticas. Rio de Janeiro: UERJ, jan./abr. 2012, v. 13, nº 27, p. 67-74.

NÓVOA, Antônio. Carta a um jovem investigador em Educação: investigar em Educação Revista da Sociedade Portuguesa de Ciências da Educação. Portugal, 2015, II ${ }^{\mathrm{a}}$ série,nº 3.

Este é um artigo de acesso aberto distribuído sob os termos da Licença Creative Commons Atribuição Não Comercial-Compartilha Igual (CC BYNC- 4.0), que permite uso, distribuição e reprodução para fins não comerciais, com a citação dos autores e da fonte original e sob a mesma licença. 